\title{
THE APPLICATION OF SIMULATION MODEL OF A MILK RUN TO IDENTIFY THE OCCURRENCE OF FAILURES
}

\author{
Fedorko, G. ; Molnar, V. ; Honus, S. ${ }^{* *}$; Neradilova, H. ${ }^{* * *} \&$ Kampf, R. \\ * Technical University of Kosice, Letna 9, 04200 Kosice, Slovak Republic \\ ${ }^{* *}$ VŠB - Technical University of Ostrava, 17. listopadu 15, 70833 Ostrava - Poruba, Czech Republic \\ *** College of Logistics, Palackeho 1381/25, 75002 Prerov, Czech Republic \\ ***** The Institute of Technology and Business in Ceske Budejovice, Okruzni 517/10, \\ 37001 Ceske Budejovice, Czech Republic \\ E-Mail: gabriel.fedorko@tuke.sk, vieroslav.molnar@tuke.sk, stanislav.honus@vsb.cz, \\ hana.neradilova@vslg.cz,kampf@mail.vstecb.cz
}

\begin{abstract}
At present, AGV systems are an important part of numerous companies and their internal logistics systems. They are used to efficiently secure different types of transport processes in order to minimize operating costs. However, their reliable operation requires adequate setting and maintenance. Computer simulation is probably the most suitable option from a wide range of engineering methods with which to meet these requirements. This paper describes the development of a simulation model in the Tecnomatix Plant Simulation program to identify critical points of failure within a specific delivery process on the basis of a Milk Run system. Based on the results obtained, an appropriate solution was determined with which to make the whole process function more efficiently and reliably. (Received in February 2018, accepted in June 2018. This paper was with the authors 1 month for 4 revisions.)
\end{abstract}

Key Words: $\quad$ AGV Simulation, Milk Run, Performance Efficiency, Delivery, Failures

\section{INTRODUCTION}

The automation of logistics processes is linked to the introduction of the latest technologies into a wide range of business operations. The primary purpose thereof is to speed up individual processes, reduce costs and enable increases in production. Process automation as such involves a number of processes, such as storage and/or transportation, and is largely implemented through automated logistics systems that perform, for instance, material handling operations [1], replace fork-lift trucks, or provide delivery services to individual workplaces $[2,3]$.

However, in order for them to operate reliably, it is essential that the whole process is appropriately designed and programmed [4]. Various methods are therefore used for its optimization and effective management, e.g. different evolutionary methodologies [5], also including genetic algorithms [6] or Ant colony algorithms [7] and mathematical models [8].

Automation mostly relates to the implementation and application of automated guided vehicle (AGV) systems [9] that may be generally defined as means of transporting and handling materials without direct human operation [10]. These systems are most frequently used in the form of individual autonomous vehicles or tractors as part of so-called logistics trains. Their great advantage is their ability to cooperate with other systems, e.g. on the basis of robotic logistics systems [11].

Each AGV system must be operated in such a way that the individual vehicles are used as much and as efficiently as possible. This is a challenging issue which is attracting a great deal of attention in the research field of logistics processes and their automation [12]. Cardarelli et al. [13] attempted to solve the given issue by applying cloud robotics architecture to effectively manage certain AGV groups. This resulted in a significant shift in the efficient management of individual vehicle routes aimed at reducing the occurrence of congestion 
zones, thereby ensuring the faster and more reliable delivery of transported materials [14]. Similarly, route-planning for AGV was also addressed by Bae and Chung [15], with their research resulting in an algorithm that can be effectively applied to the planning of transport routes for a multi-AGV system [16]. In all cases, computer simulation was applied. This is because it is currently considered to be a very powerful tool with which to solve issues relating to logistics and process automation [17]. However, consideration must also be given to, for example, the production technology, the volume and scale of production, and/or the technological equipment and its performance. In terms of AGV operating systems, Milk Run (largely seen in the automotive industry) systems are very often applied [18].

In recent years, logistics auditing has also been brought to the forefront in connection with the previously mentioned automation [19]. On the one hand, a detailed logistics audit is required prior to the implementation of any automation - to prove the necessity and appropriateness thereof. On the other hand, a logistics audit is a means by which to evaluate the efficiency of operating such automated systems and classifying their effectiveness. The audit and its roles were discussed by Gaidabrus [20], who emphasizes its key aspects and describes important indicators to focus on. A logistics audit also enables the drawing up of a systematic overview of individual operations and the evaluation of them [21].

For this type of audit, a range of proven methods and procedures must be applied to obtain relevant information with sufficient reporting value [22]. One such method is that of computer simulation. This was examined by Wang and Chen [17], who evaluated the efficiency of logistics processes in the automotive industry, and who eventually confirmed several possibilities for applying this method to obtain a wide range of evaluation information and parameters. Xiao et al. [23] used a specific computer simulation to evaluate logistics processes and to improve their performance.

Based on the above information, the authors conducted specific research in order to explore the possibilities for utilising computer simulation to obtain information on the operation of logistics trains with the use of AGV in a particular delivery process involving the Milk Run method. The objective was to put forward a simulation model that would accept the basic characteristics of the AGV operating system while accepting the delivery process principles, including the Milk Run. In addition, the research set out to verify what information can be obtained in terms of logistics audit requirements, and what modelling possibilities there are for the given delivery process in the Milk Run system when combined with AGVbased logistics trains.

\section{MATERIALS AND METHODS}

Nowadays, AGV systems are largely used for intralogistics. Intralogistics is seen as an area that includes internal company technology (material flows and logistics) and its role is therefore to deal with the organization, management, implementation and optimization of internal material flows and materials handling.

When implementing any AGV in an intralogistics system, it is necessary to focus on the following three basic questions:

1. What type of AGV system will be used?

2. What method of AGV navigation will be implemented?

3. What kind of worker safety/protection will be applied?

Exact and clear answers to these questions are very important for the whole system to function correctly. Using AGV systems for intralogistics complies with the current trend to adopt the Industry 4.0 philosophy. This philosophy aims, among other things, to automate repeated logistics processes, which the implementation of AGV systems supports. 


\subsection{Method of computer simulation and AGV systems}

With regards to AGV systems, the method of computer simulation offers a number of distinct advantages, which makes it irreplaceable when it comes to the design and operation of these systems. In order to use this method and apply it, basic groups of information are required, which in turn can help to generate groups of information for evaluation purposes (see Fig. 1).

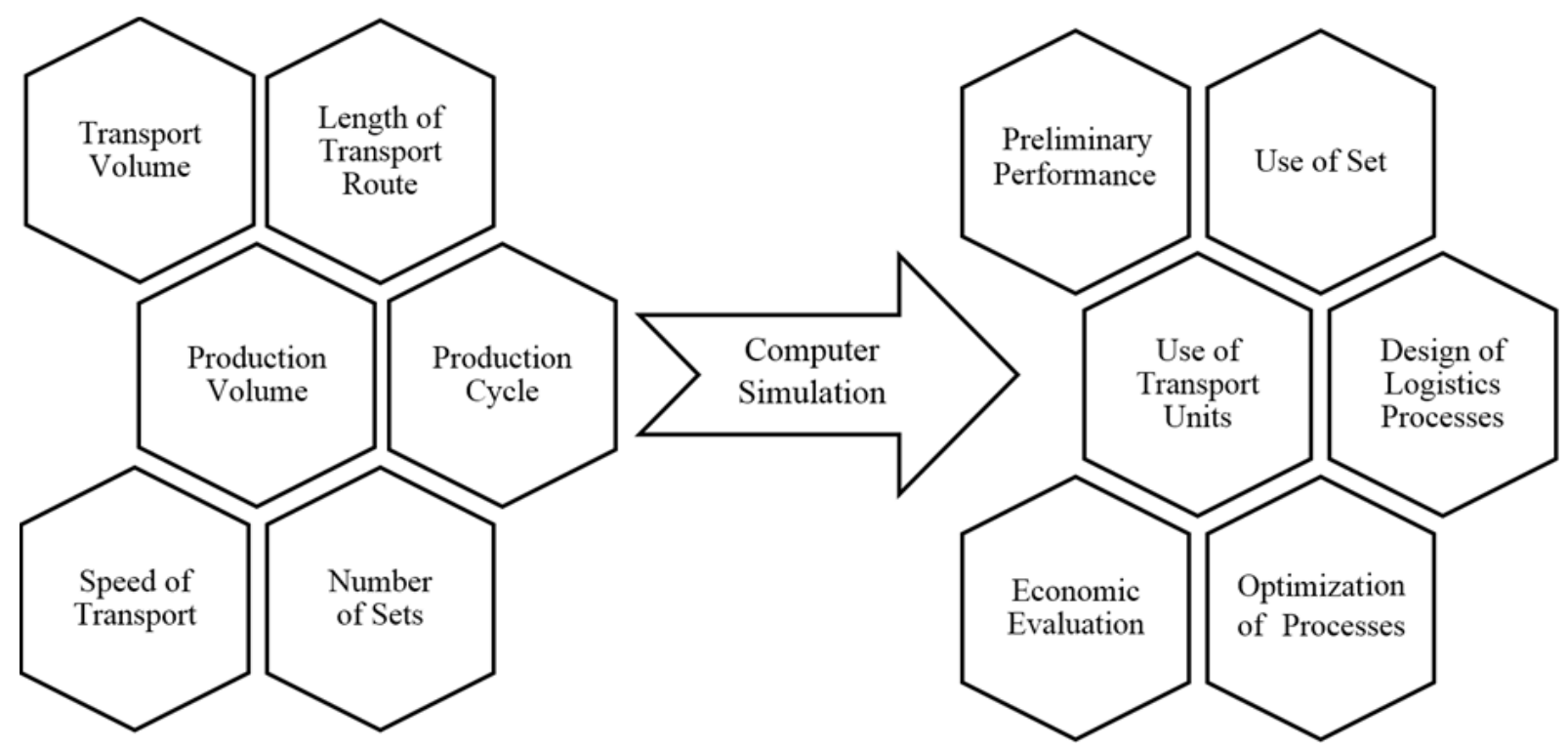

Figure 1: Overview of groups of information related to the application of computer simulation to AGV systems.

Another issue that needs to be addressed is the selection of appropriate software for conducting simulation experiments. During the selection process, it is essential to always consider what results and information are expected, or what is to be explored. At present, there are various software tools available that may be used in logistics, i.e. tools that mostly enable the development of discrete simulation models. However, there are also simulation programs that enable the development of continuous and combined models that may also be used in logistics.

With respect to AGV systems and the complexity of the logistics processes and operations, it is advisable to select software that enables an AGV set to be tracked not as a complex entity, but rather as a set composed of several entities that influence each other. At the same time, it is recommended that each of these entities (as far as possible) be separately traceable and measurable.

\subsection{Simulation model for AGV set}

When developing a simulation model for a specific AGV set, it must primarily be based on the expected outputs and required information. On this basis, it is therefore possible to choose from all three basic types of simulation models (discrete, continuous, combined).

The discrete and combined models are the preferred choice when it concerns short-term or detailed analyses where the main focus is on precisely specified parameters. In contrast, a continuous simulation model should be developed when simulating a given AGV set with a long-term time horizon, and where detailed information is irrelevant or unnecessary. A comparison of the outputs from a discrete simulation model and a continuous simulation model for AGV sets is presented in Fig. 2. The difference is very clear. The continuous model shows the AGV set results continuously (over time), whilst the discrete model shows the detailed results for individual operations. 

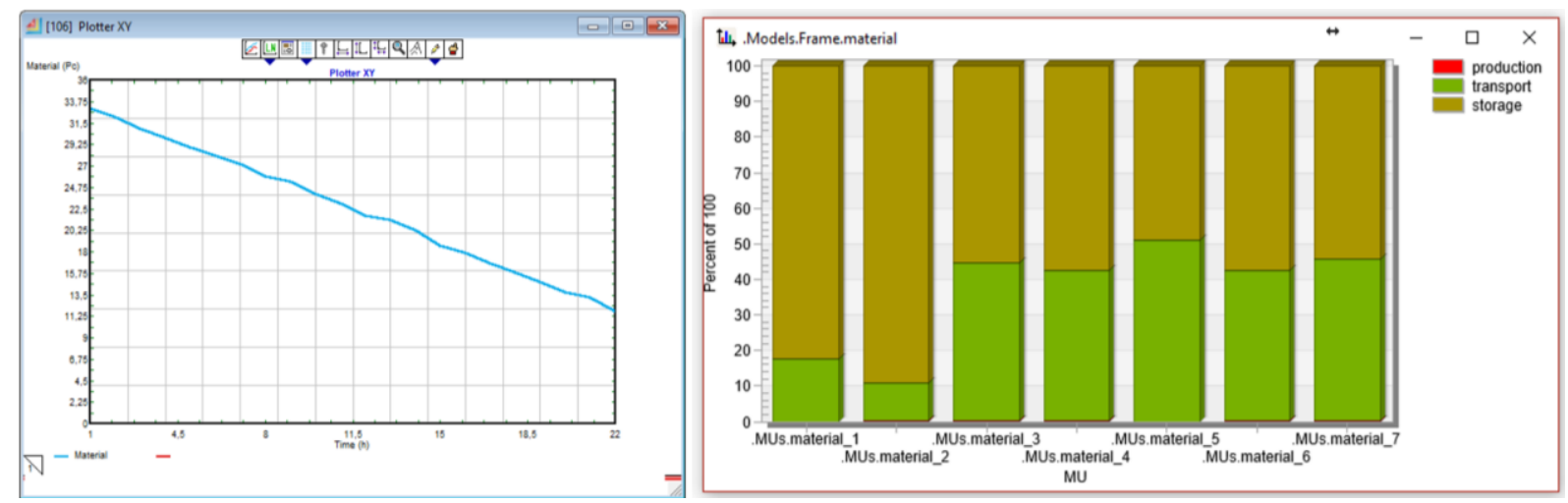

Figure 2: Example of continuous and discrete simulation model outputs for logistics processes of an AGV set.

\section{THEORY / CALCULATION - MILK RUN SYSTEM CHARACTERISTICS}

A Milk Run system is, in terms of logistics processes, a very common means of delivery to individual workplaces. The main principle behind the system is the delivery of handling units with required materials and the simultaneous collection of empty units at a precisely specified time (see Fig. 3). This materials transport system is characterized by fixed transport routes and constant volumes of materials transported on them.

By applying the system to company logistics, efficient and cost-effective transport routes can be set, thereby minimizing time losses. At the same time, it ensures that individual workplaces are only accessed once during a single run, which (at the optimal level and under the right conditions) minimizes deadhead transportation.

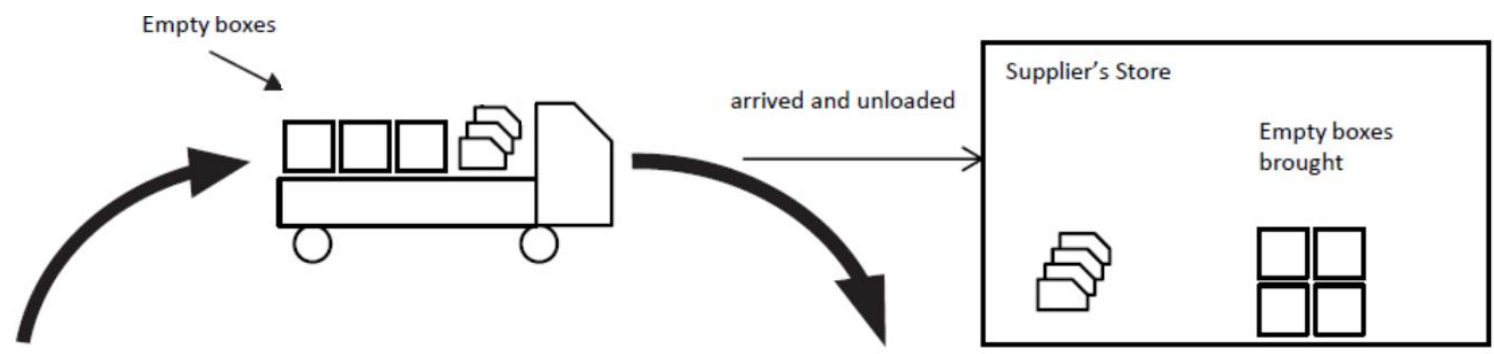

plant

supplier

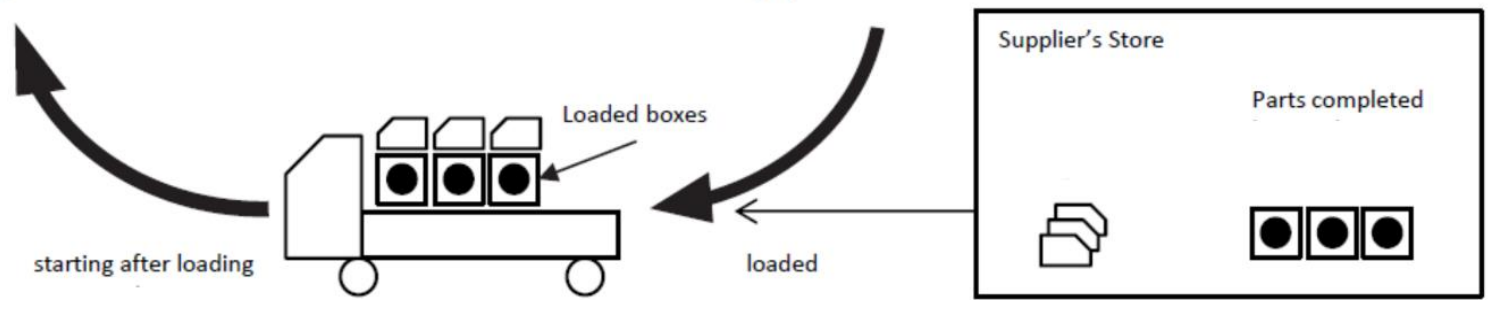

Figure 3: Principle of the Milk Run system [24].

When taking into consideration the environment in which such a system can be applied, it can be divided into an external Milk Run and an internal Milk Run. The external one provides transportation outside the internal company environment, whereas the internal one operates purely within the internal environment.

Generally speaking, a Milk Run system is used to provide regular deliveries of materials, minimize unplanned material movements, and save time and space required for materials storage. 
In terms of their operation, two basic categories of vehicles can be used for an internal Milk Run system - automated guided vehicle (AGV) (see Fig. 4), or a vehicle directly operated by its operator.

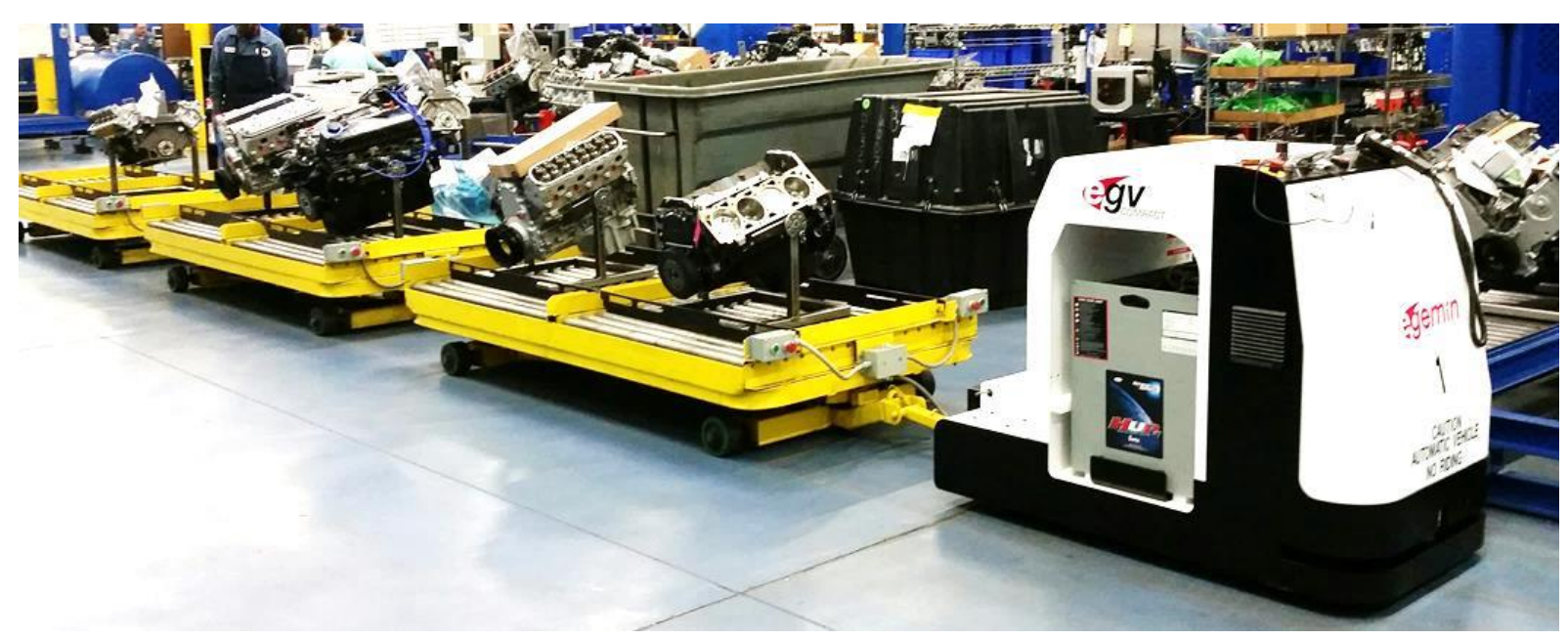

Figure 4: Example of the use of an Automated Guided Vehicle (AGV) in a Milk Run system [25].

\subsection{Determination of the number of vehicles in an AGV set and their operation in a Milk Run system}

Determining the number of vehicles that should form an individual AGV set is a very demanding task which is influenced by several parameters, such as the type of production, transportation volume and transport route. This has been the subject of research published in various publications, for example by Egbelu [26], Eq. (1):

where:

$$
N=\left[\left(\sum_{i=1}^{n} \sum_{j=1}^{n} D_{i j} / V\right)+\left(\sum_{i=1}^{n} \sum_{j=1}^{n} f_{i j}\right) \cdot\left(t_{u}+t_{l}\right)\right] /(60 T-t)
$$

$n$ - number of workplaces;

$f_{i j}$ - expected number of loaded trips required between a workplace $i$ and a workplace $j$ during a period or a shift;

$D_{i j}$ - estimated empty and loaded travel distance between the workplaces $i$ and $j$;

$T$ - length of the period or the shift during which the $f_{i j}$ exchange occurs;

$V$ - average vehicle travel speed;

$t_{l}$ - time period it takes to load a vehicle;

$t_{u}$ - time period it takes to unload a vehicle;

$t$ - expected time loss of each vehicle during time period $T$ due to battery change.

Similarly, it is difficult to determine the manner in which individual sets should be operated because a wide range of parameters and limitations need to be taken into consideration. In relation to $\mathrm{AGV}$ sets, there are discussions in scientific literature on proposed methodologies for unifying and regulating this issue, for example Le-Anh [27] in Table I.

\subsection{Performance evaluation of AGV in a Milk Run system}

In order for a Milk Run system to continue to function and operate efficiently, it is necessary to regularly evaluate it on the basis of selected indicators (see Table II). These indicators must have sufficient reporting value with regards to the systems condition and efficiency, and possibly indicate existing problems and shortcomings. 
Table I: Guidelines for selecting an appropriate vehicle scheduling system [27].

\begin{tabular}{|c|c|c|c|c|c|c|c|c|c|c|}
\hline \multicolumn{9}{|c|}{ Criteria } \\
\hline \multicolumn{3}{|c|}{ Guide - path system } & $\begin{array}{c}\text { Ability of SFC system to } \\
\text { deal with complicated } \\
\text { controllers }\end{array}$ & \multicolumn{2}{|c|}{$\begin{array}{c}\text { Degree of stochasticity of jobs' } \\
\text { arrivals }\end{array}$} & \multicolumn{3}{|c|}{ Job density } \\
\hline $\begin{array}{c}\text { Single } \\
\text { loop }\end{array}$ & Tandem & Conventional & Yes & No & No & Low & Medium & High & Low & High \\
\hline$D$ & $D$ & $S / D$ & $S / D$ & $D$ & $S($ off $)$ & $S($ on $)$ & $S($ on $) / D$ & $S($ on $) / D$ & $S(r) / D$ & $S / D(r)$ \\
\hline
\end{tabular}

"SFC: Shop floor control; $D$ : Dispatching; $S$ : Scheduling; on: Online; off: Offline; $r$ : Recommended.

Table II: Overview of parameters for AGV evaluation in a Milk Run system.

\begin{tabular}{|l|c|c|c|}
\hline \multicolumn{1}{|c|}{ Parameter } & $\begin{array}{c}\text { Time } \\
(\mathrm{min})\end{array}$ & $\begin{array}{c}\text { Performance - length } \\
(\mathrm{m})\end{array}$ & $\begin{array}{c}\text { Performance - volume } \\
\text { (pieces) }\end{array}$ \\
\hline Turnaround time & $\bullet$ & & $\bullet$ \\
\hline Transport volume & & $\bullet$ & $\bullet$ \\
\hline Transport performance & & $\bullet$ & $\bullet$ \\
\hline Driving utilization coefficient & & $\bullet$ & \\
\hline Capacity utilization coefficient & & $\bullet$ & \\
\hline Driving performance & & & $\bullet$ \\
\hline
\end{tabular}

\section{SIMULATION MODEL}

The presented simulation model consists of three basic parts, namely a sub-model of an AGV system transport route, a workplace sub-model and a supermarket sub-model.

\subsection{Operating characteristics}

The entire simulation model consists of 23 workplaces with deliveries made by a given AGV set in a Milk Run system. The basic characteristics are shown in Table III and Table IV. The parameters used for the simulation are the result of mutual interactions monitored during the course of materials consumption at the individual workplaces and the movement of handling units.

Table III: Characteristics of workplaces 1 to 11 .

\begin{tabular}{|l|c|c|c|c|c|c|c|c|c|c|c|}
\hline & $\mathbf{1 .}$ & $\mathbf{2 .}$ & $\mathbf{3 .}$ & $\mathbf{4 .}$ & $\mathbf{5 .}$ & $\mathbf{6 .}$ & $\mathbf{7 .}$ & $\mathbf{8 .}$ & $\mathbf{9 .}$ & $\mathbf{1 0 .}$ & $\mathbf{1 1 .}$ \\
\hline Tact time & 3.03 & 3.25 & 3.25 & 3.23 & 3.22 & 3.22 & 3.22 & 3.22 & 3.04 & 3.04 & 3.22 \\
\hline Number of pallets & 2 & 2 & 2 & 2 & 2 & 2 & 2 & 2 & 2 & 2 & 2 \\
\hline Unit capacity & 162 & 400 & 300 & 100 & 30 & 30 & 24 & 24 & 60 & 60 & 25 \\
\hline Handling time & 0.5 & 0.5 & 0.5 & 0.5 & 0.5 & 0.5 & 0.5 & 0.5 & 0.5 & 0.5 & 0.5 \\
\hline
\end{tabular}

Table IV: Characteristics of workplaces 12 to 23.

\begin{tabular}{|l|c|c|c|c|c|c|c|c|c|c|c|c|}
\hline & $\mathbf{1 2 .}$ & $\mathbf{1 3 .}$ & $\mathbf{1 4}$ & $\mathbf{1 5 .}$ & $\mathbf{1 6}$ & $\mathbf{1 7 .}$ & $\mathbf{1 8}$ & $\mathbf{1 9 .}$ & $\mathbf{2 0 .}$ & $\mathbf{2 1 .}$ & $\mathbf{2 2 .}$ & $\mathbf{2 3 .}$ \\
\hline Tact time & 3.22 & 3.23 & 4.42 & 3.22 & 3.22 & 3.23 & 3.23 & 3.04 & 3.04 & 3.21 & 3.21 & 3.21 \\
\hline Number of pallets & 2 & 2 & 2 & 2 & 2 & 2 & 2 & 2 & 2 & 2 & 2 & 2 \\
\hline Unit capacity & 10 & 100 & 80 & 50 & 50 & 100 & 180 & 60 & 60 & 80 & 80 & 80 \\
\hline Handling time & 0.5 & 0.5 & 0.5 & 0.5 & 0.5 & 0.5 & 0.5 & 0.5 & 0.5 & 0.5 & 0.5 & 0.5 \\
\hline
\end{tabular}

\subsection{Transport route and characteristics of the AGV set}

The outlined transport route for the given AGV set was based on the layout (to scale) of the production and assembly hall presented in Fig. 5. As part of the model development, the entire route was divided into several sub-sections, each with a constant length and an unlimited number of vehicles running along them. The total length of the route is $2,520 \mathrm{~m}$. 


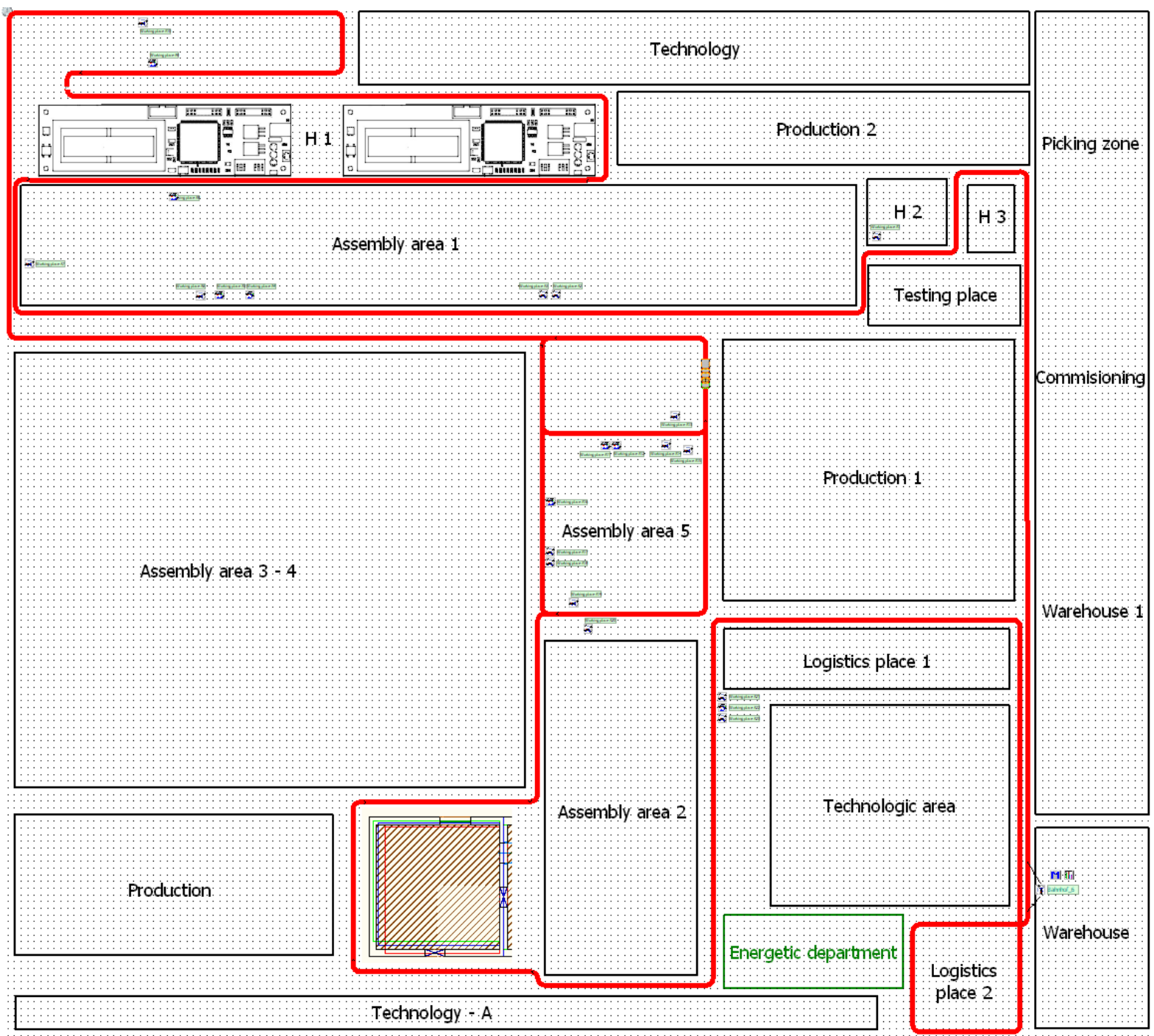

Figure 5: Diagram of the transport route for the Milk Run system.

\subsection{Workplace sub-model}

The main principle of this model, developed with the use of the following block diagram (see Fig. 6), is based on two full boxes and the real (actual) functioning of the whole process.

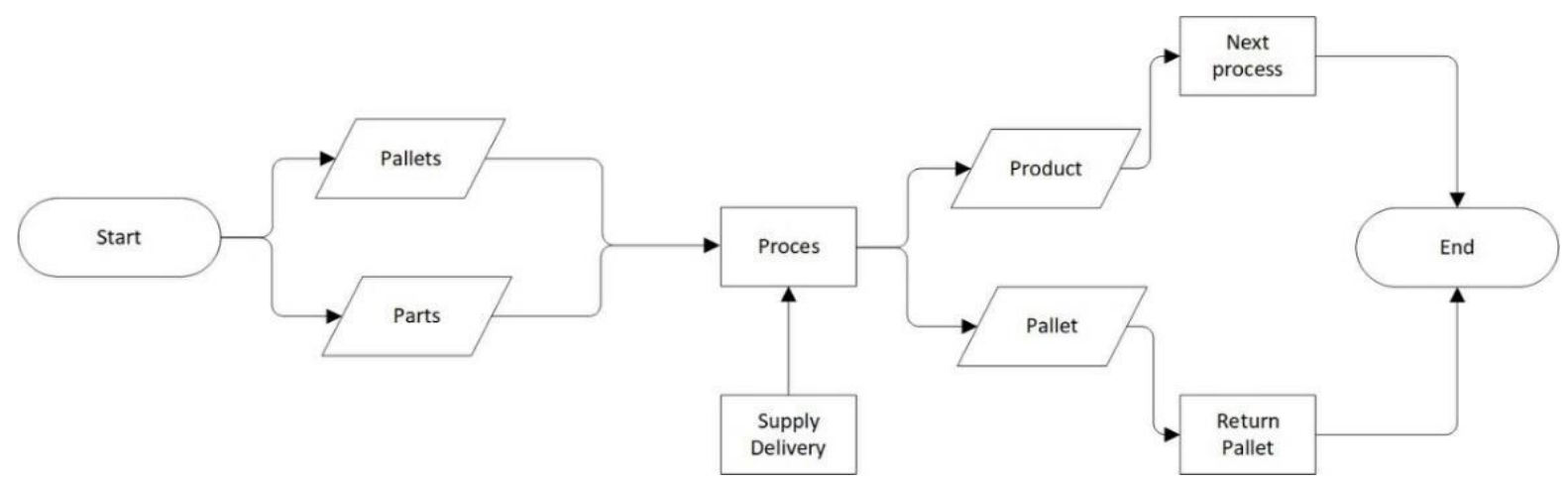

Figure 6: Block diagram of workplace sub-model.

At the start of the simulation, each workplace always contains two full boxes. A certain amount of material (components) is sequentially taken from them in a fixed time step according to the technology used. Having been emptied, the first box moves to the pick-up 
zone awaiting the arrival of the AGV set that will transport it back to the supermarket for replenishment and return to the workplace. The replenishment of a single handling unit (i.e. a box) and its transport back to the assembly hall must always be carried out while the second box is being processed. Non-compliance with this condition would result in interruptions to production and the occurrence of failures, which is not desirable.

The sub-model, based on the process described above, was subsequently transformed using Tecnomatix Plant Simulation blocks (see Fig. 7).

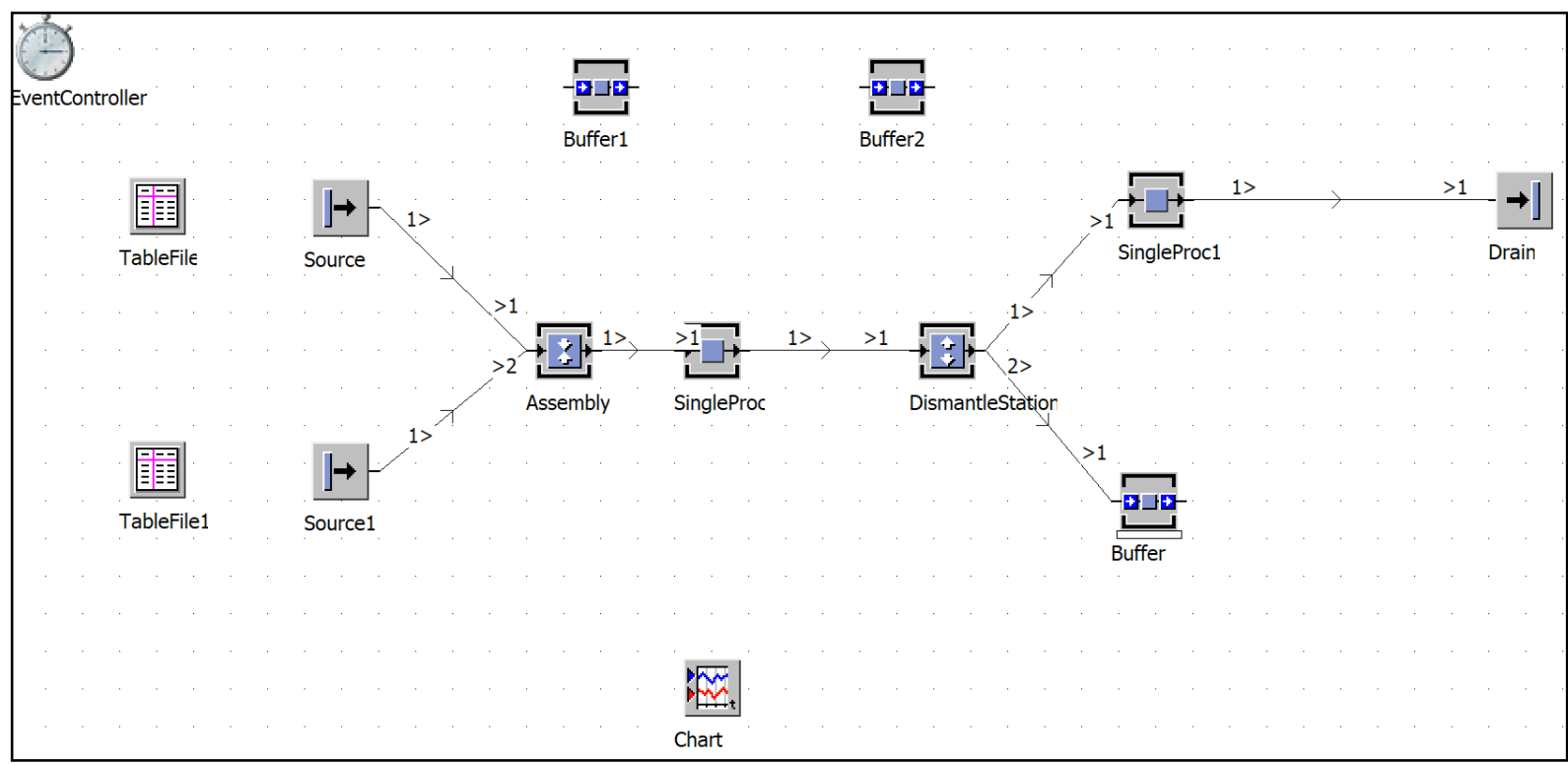

Figure 7: Transformation of the workplace sub-model.

The TableFile_p and TableFile_m blocks have a defined amount of material and boxes that are available at the beginning of the process. Using the Assembly block, a certain batch (a box containing materials) is generated and moved to the SingleProc block representing a space for the full box storage (during the sequential removal of materials), included in the respective technological process, which itself is represented by three blocks, i.e. DismantleStation, SingleProc_Pro and Buffer. After the box has been processed, it is stored in the pick-up zone (represented by the Buffer block) awaiting the arrival of the AGV set (train) that will load the box and transport it to the replenishment point (provided that the required transport capacity is available). The loading and unloading of materials are carried out by the TransferStation blocks.

The workplace sub-model also includes the monitoring of available quantities of materials. This is performed by two types of blocks, namely the Buffer blocks (for monitoring changes in the number of pieces of the available material) and the Chart blocks (for graphical visualization). The entire process is realized using a sequence generated according to the complementary programming method in the SimTalk language (see Fig. 8).

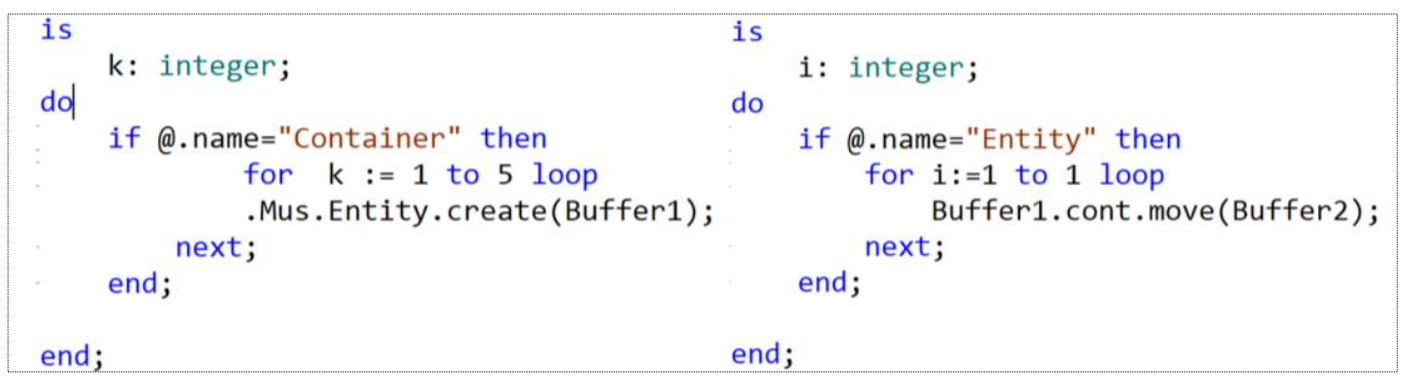

Figure 8: Example of a SimTalk sequence for monitoring quantities of materials at a given workplace. 


\subsection{Supermarket sub-model}

The principle behind this sub-model is a little more complicated because it involves the reception of empty boxes, their distribution to a designated order-picking point, as well as their subsequent placement on an AGV set (see Fig. 9). The supermarket sub-model works as follows: the presence of a box in the supermarket is the trigger to fill it, whereas the presence of a box in the supermarket pick-up zone is the trigger for the full box to be collected and transported.

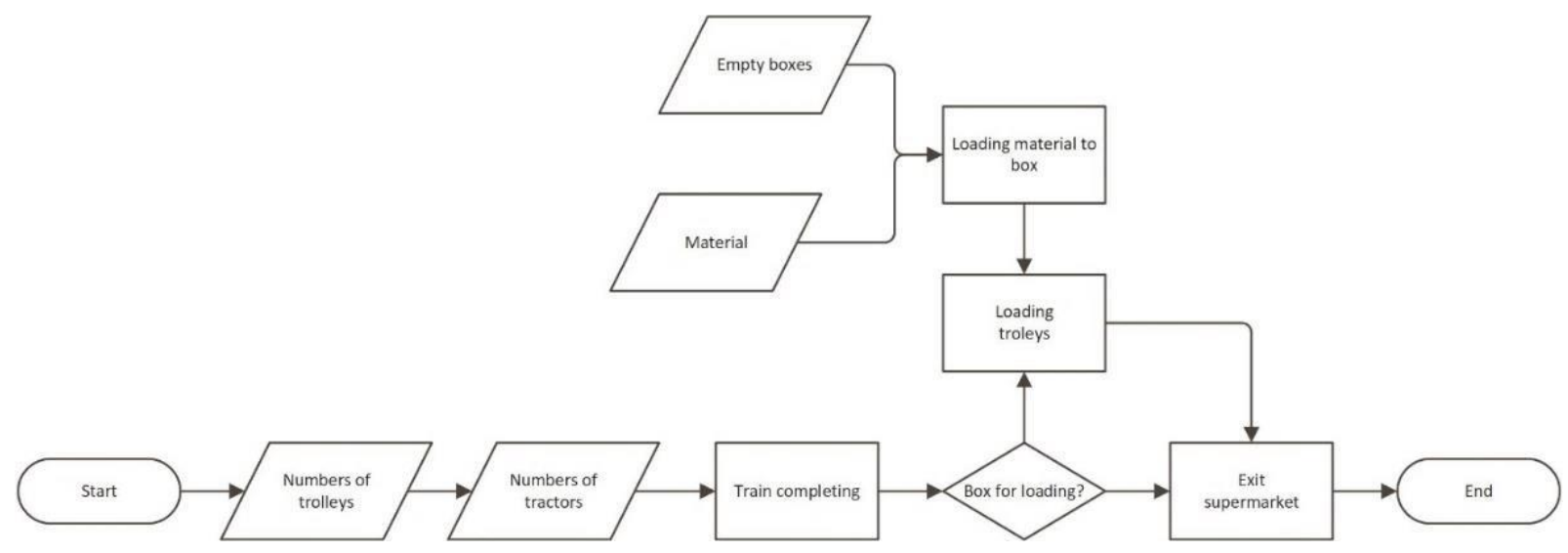

Figure 9: Block diagram of supermarket sub-model.

The AGV set passes through the supermarket making stops for fixed periods of time (related to the loading and unloading of materials) and leaving at specified times. The number of boxes and vehicles in the Milk Run system are also fixed.

An example of the transformation of the supermarket operations (with the use of Tecnomatix Plant Simulation blocks) is presented below (see Fig. 10).

The formation of the AGV set in the supermarket is determined by a group of TableFile and Source blocks. The combination (tractor and trolleys) is created using the complementary programming method in the SimTalk language.

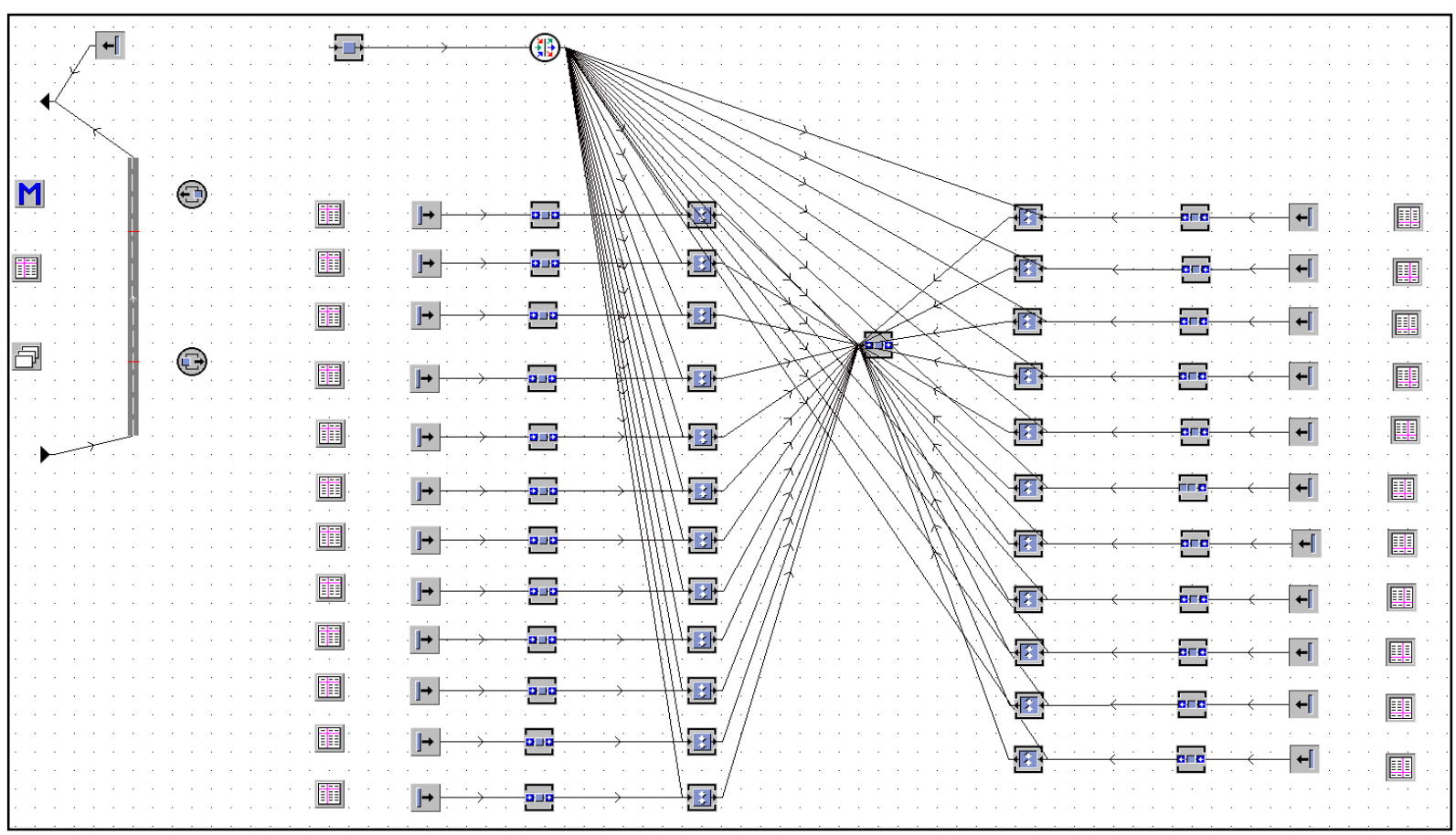

Figure 10: An example of a supermarket sub-model. 
At the start of the simulation, the AGV set moves along the defined route and performs a cycle, which involves the delivery of full boxes and the removal of empty ones.

The supply of materials in the supermarket is generated by a pair of TableFile and Source blocks. The generated entity is stored in the Buffer block, which is linked to the Assembly block, which in turn secures the configuration of the materials and the handling of empty box(es) to form a consignment. The consignment is subsequently distributed to another Buffer block (representing the supermarket pick-up zone) awaiting loading onto an empty trolley in the AGV set. Having been loaded, the set is dispatched for transport along its defined route.

\subsection{Formation of an AGV set}

An AGV set was created using the complementary programming method in the SimTalk language. The following short program (see Fig. 11) is taken from the Method block.

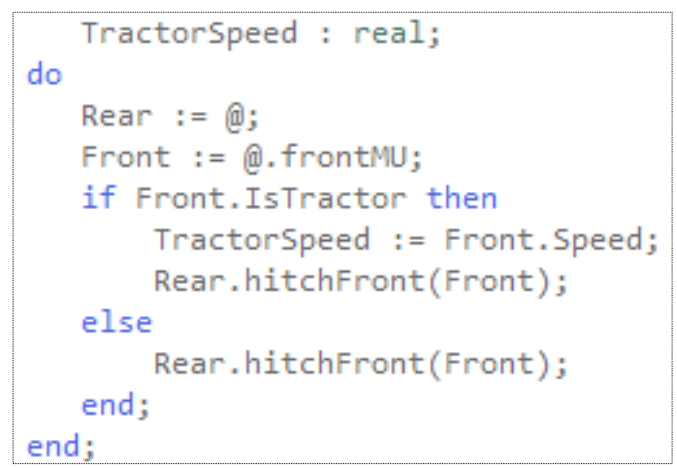

Figure 11: Example of program for configuring vehicles in an AGV set.

By utilising the above-recorded sequence, a fixed configuration of units in an AGV set is determined, whereby the tractor is always the lead vehicle and the trolleys follow. In order to facilitate the transport of the materials, the dimensions and capacity characteristics of the trolleys are clearly defined (including the defined types of materials they can carry in the boxes). For the simulation, the AGV set consisted of one tractor and four trolleys of three different types.

\section{RESULTS}

The simulation model, having been confirmed and validated, was applied to the analysis of the proposed Milk Run system in order to verify that it functioned correctly and was capable of measuring the delivery performance of the AGV set (one tractor and four trolleys - Trolley $\mathrm{Nr} \_$1, Trolley Nr_2, Trolley Nr_3, Trolley Nr_4).

To properly reflect real operating conditions, the length of the simulation experiments was always 24 hours continuous operation without any maintenance breaks. The constant speed of the set was set at $1.5 \mathrm{~m} / \mathrm{s}$.

The obtained results identified three problem areas at workstations WP 13, WP 14 and WP 15. In all cases, the recognized failures resulted in a short-term outage and interruption to the production process throughout the entire technological unit.

The first failure was identified at workplace WP 13. It occurred after approximately 19 hours of operation, upon completion of the first replacement of an empty transport unit with a filled one. Similar failures occurred at workplaces WP 14 and WP 15 (see Fig. 12), resulting in production outages due to a lack of materials. 


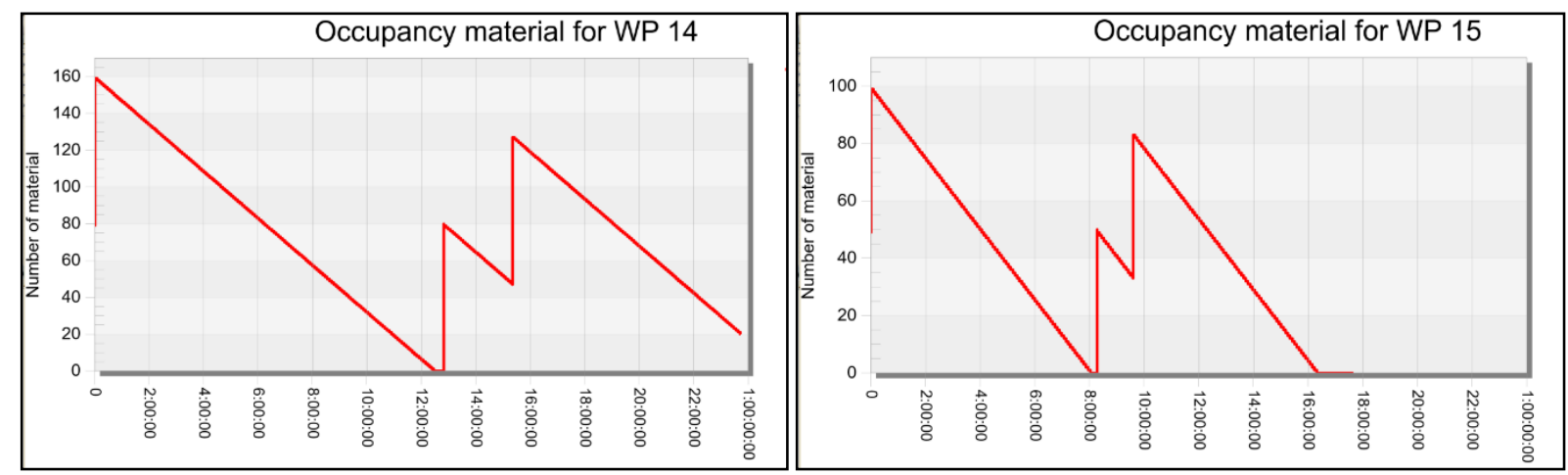

Figure 12: Material status at workplace WP 14 and at workplace WP 15 during one 24-hour period.

The occurrence of just one of these failures is considered undesirable, let alone three. All the more important is the fact that they occurred simultaneously and repeated in regular cycles, thereby significantly disrupting the consistency of production. In order to determine the causes of these failures, particular attention was paid to the Milk Run system itself and the AGV set used, and more specifically to the use of the individual trolleys (see Fig. 13). This focus was based on the assumption that even if the set included up to four trolleys, they were not mutually replaceable because it concerned trolleys of three different categories.

The results also revealed the uneven loading of the individual trolleys (ranging from $26.12 \%$ to $79.6 \%$ ). An additional analysis showed that deliveries to the previously identified critical points were carried out by Trolley $\mathrm{Nr}_{-} 1$, i.e. the most frequently used trolley. As a result, the failures were determined to have been caused by the excessive use of the respective trolley or the disproportionate use of the individual trolleys.

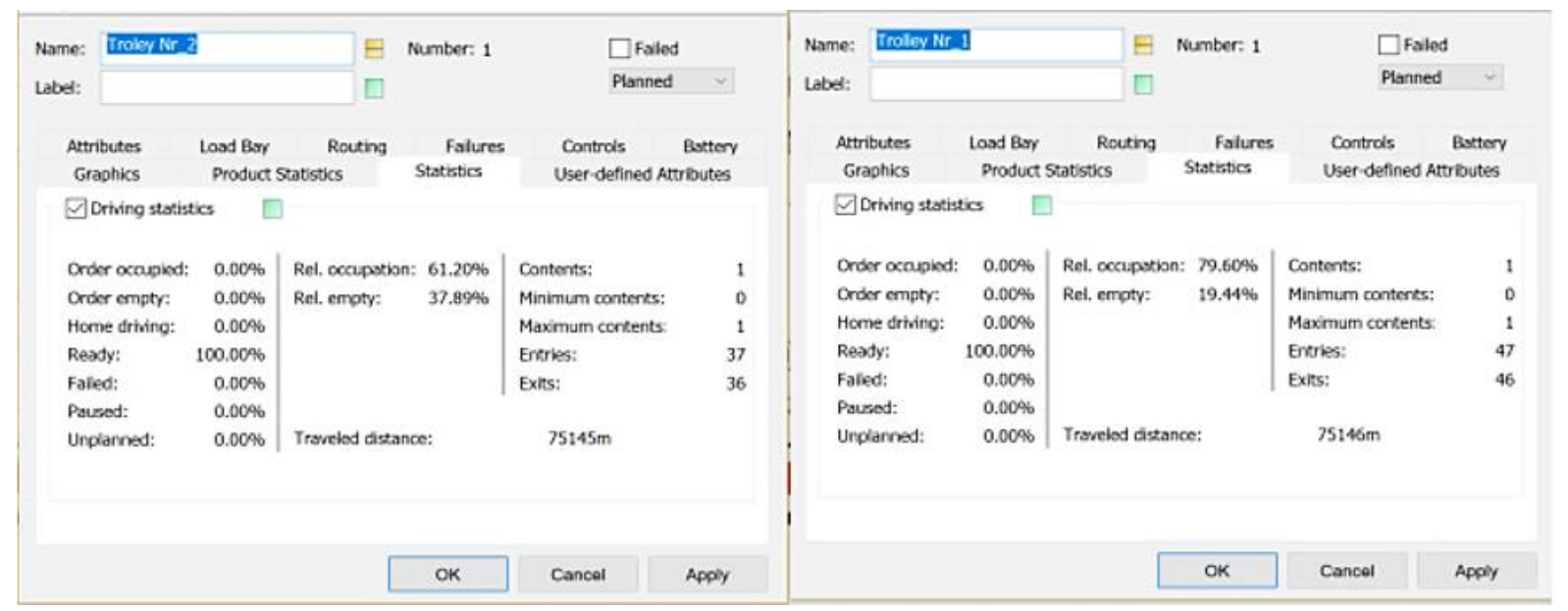

Figure 13: Example of capacity utilisation of individual trolleys (Trolley Nr_2 - Trolley Nr_1).

To verify the findings, the order-picking and reconsignment processes for the individual boxes were also examined (see Fig. 14). No serious errors were detected and the process ran continuously. It was therefore concluded that the occurrence of the failures was caused by the aforementioned excessive use of Trolley $\mathrm{Nr}_{-} 1$.

Based on the knowledge acquired and the identified causes of the failures within the production process, a solution was sought which would completely eliminate their occurrence and prevent interruptions to production. The simplest solution appeared to be to make an adjustment to Trolley Nr_4 in terms of transport capacity, so that, when necessary, it could replace Trolley Nr_1. Other options (adding another trolley or increasing the capacity of the boxes) were not considered for various reasons, in particular economic. The impact of the proposed change can be seen in Fig. 15. 

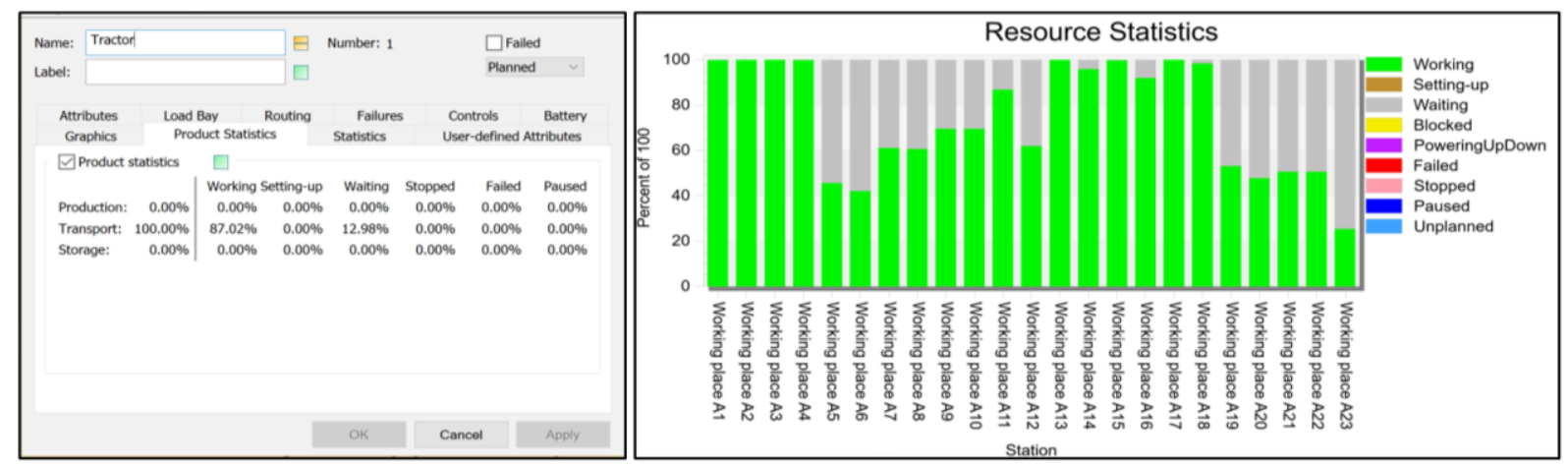

Figure 14: Vehicle set utilisation and order-picking for individual workstations.
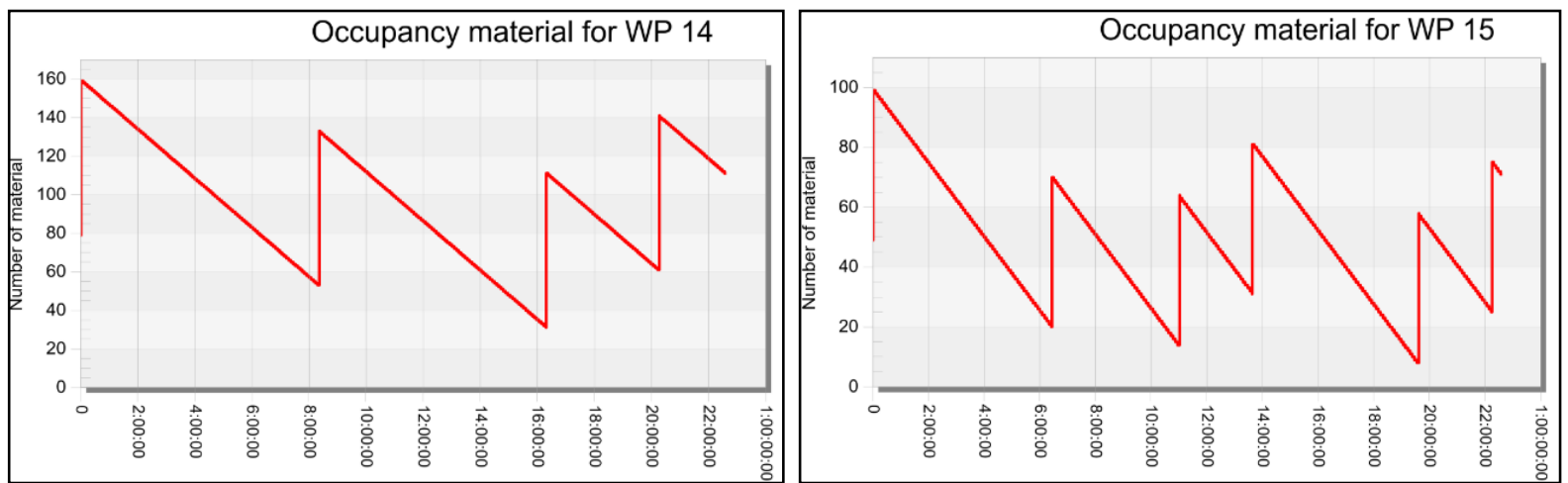

Figure 15: Material status development at workplace WP 14 and at workplace WP 15 during one 24-hr period after the change.

Overall, significant positive changes were observed in the material delivery process at the critical workplaces. The proposed solution was subsequently put into practice and the production process has been running without any interruptions.

\section{CONCLUSION}

The use of computer simulation is not limited to merely verifying the accuracy, reliability and functioning of AGV systems. On the contrary, computer simulation also offers a wide range of options for dealing with other issues relating to internal company logistics. These include, for instance, the optimization of control systems, the optimization of supplies, increasing the capacity utilization of transportation vehicles and production, etc.

A very important element in solving such issues is the selection of a suitable simulation tool that will be able to effectively address them. At present, there are many powerful software tools available on the market for company logistics. Even though only one method of application was presented in this paper, AGV and Milk Run systems may also be used to look into other problem areas. Further research is therefore required into how the use of individual means of transport can be increased and how the operational efficiency of the aforementioned logistics systems can be improved.

This article describes an application of the supplementary programming, which is determined for extension of functionality concerning the computer simulation methods. The results of the performed scientific research offer an opportunity to apply this method as a robust tool. According to the obtained results it is possible to say that this method is very suitable for scientific research of the AGV systems as well as other logistic processes. There is observed, with regard to the given results, dependence between the workplace supply systems and reliability of their functioning. The proposed method is a universal procedure, which can be utilized for solution of other similar problem tasks. 


\section{ACKNOWLEDGEMENT}

This work is a part of these projects VEGA 1/0063/16, VEGA 1/0403/18, KEGA 018TUKE-4/2016, APVV-17-0235, SP2018/69, LO1404.

\section{REFERENCES}

[1] Cho, J.-H.; Kim, Y.-T. (2017). Design of autonomous logistics transportation robot system with fork-type lifter, International Journal of Fuzzy Logic and Intelligent Systems, Vol. 17, No. 3, 177-186, doi:10.5391/IJFIS.2017.17.3.177

[2] Neradilova, H.; Fedorko, G. (2017). Simulation of the supply of workplaces by the AGV in the digital factory, Procedia Engineering, Vol. 192, 638-643, doi:10.1016/j.proeng.2017.06.110

[3] Berman, S.; Edan, Y. (2002). Decentralized autonomous AGV system for material handling, International Journal of Production Research, Vol. 40, No. 15, 3995-4006, doi:10.1080/ $\underline{00207540210146990}$

[4] Li, Y.; Yao, X.; Zhou, J. (2016). Multi-objective optimization of cloud manufacturing service composition with cloud-entropy enhanced genetic algorithm, Strojniski vestnik - Journal of Mechanical Engineering, Vol. 62, No. 10, 577-590, doi:10.5545/sv-jme.2016.3545

[5] Hou, L.; Liu, Z.; Shi, Y.; Zheng, X. (2016).Optimizing machine assignment and loop layout in tandem AGV workshop by co-evolutionary methodology, Proceedings of the 2016 IEEE $20^{\text {th }}$ International Conference on Computer Supported Cooperative Work in Design (CSCWD), 263268, doi:10.1109/CSCWD.2016.7565999

[6] Han, Z.; Wang, D.; Liu, F.; Zhao, Z. (2017). Multi-AGV path planning with double-path constraints by using an improved genetic algorithm, PLOS ONE, Vol. 12, No. 7, Paper e0181747, 16 pages, doi: 10.1371 journal.pone. 0181747

[7] Zhao, J.; Fei, L. (2012). The optimal path planning for warehouse logistics AGV based on ant colony algorithm, International Conference on Electrical and Control Engineering (ICECE 2015), 180-185

[8] Archila, J. F.; Becker, M. (2013). Mathematical models and design of an AGV (Automated Guided Vehicle), Proceedings of the 2013 IEEE $8^{\text {th }}$ Conference on Industrial Electronics and Applications (ICIEA), 1857-1862, doi:10.1109/ICIEA.2013.6566670

[9] Sankari, J.; Imtiaz, R. (2016). Automated guided vehicle (AGV) for industrial sector, Proceedings of the $10^{\text {th }}$ International Conference on Intelligent Systems and Control (ISCO'16), 5 pages, doi:10.1109/ISCO.2016.7726962

[10] Beinschob, P.; Meyer, M.; Reinke, C.; Digani, V.; Secchi, C.; Sabattini, L. (2017). Semiautomated map creation for fast deployment of AGV fleets in modern logistics, Robotics and Autonomous Systems, Vol. 87, 281-295, doi:10.1016/j.robot.2016.10.018

[11] Jaiganesh, V.; Kumar, D. J.; Girijadevi, J. (2014). Automated guided vehicle with robotic logistics system, Procedia Engineering, Vol. 97, 2011-2021, doi:10.1016/j.proeng.2014.12.444

[12] Ferbar Tratar, L. (2016). The comprehensive energy resource management for essential reduction of the total cost, Strojniski vestnik - Journal of Mechanical Engineering, Vol. 62, No. 11, 685694, doi:10.5545/sv-jme.2016.3994

[13] Cardarelli, E.; Digani, V.; Sabattini, C.; Secchi, C.; Fantuzzi, C. (2017). Cooperative cloud robotics architecture for the coordination of multi-AGV systems in industrial warehouses, Mechatronics, Vol. 45, 1-13, doi:10.1016/j.mechatronics.2017.04.005

[14] Tomasikova, M.; Sojcak, D.; Nieoczym, A.; Brumercik, F. (2017). Experimental data in vehicle modeling, LOGI - Scientific Journal on Transport and Logistics, Vol. 8, No. 1, 82-87, doi: $10.1515 / \operatorname{logi}-2017-0010$

[15] Bae, J.; Chung, W. (2017). A heuristic for a heterogeneous automated guided vehicle routing problem, International Journal of Precision Engineering and Manufacturing, Vol. 18, No. 6, 795-801, doi:10.1007/s12541-017-0095-3

[16] Hu, H.; Shi, L.; Ma, H.; Ran, B. (2017). Stability of the supply chain based on disruption classification, Technical Gazette, Vol. 24, No. 4, 1187-1195, doi:10.17559/TV-20170723084826 
[17] Wang, Y. R.; Chen, A. N. (2016). Production logistics simulation and optimization of industrial enterprise based on Flexsim, International Journal of Simulation Modelling, Vol. 15, No. 4, 732741, doi:10.2507/IJSIMM15(4)CO18

[18] Strachotova, D.; Pavlistik, J. (2017). The assessment of efficiency of in-plant milk-run distribution system in cable manufacturing for automotive industry, Soliman, K. S. (Ed.), Sustainable Economic Growth, Education Excellence, and Innovation Management Through Vision 2020, Int. Business Information Management Association, Norristown, 105-109

[19] Kapustina, L. M.; Chovancova, M.; Klapita, V. (2017). Application of specific theory of constraints technique for the identification of main causes of negative consequences within procurement logistics, LOGI - Scientific Journal on Transport and Logistics, Vol. 8, No. 1, 5663, doi:10.1515/logi-2017-0007

[20] Gaidabrus, N. V. (2015). Key aspects of logistics services audit, Marketing and Management of Innovations, Vol. 2015, No. 2, 234-242

[21] Van Landeghem, R.; Persoons, K. (2001). Benchmarking of logistical operations based on a causal model, International Journal of Operations \& Production Management, Vol. 21, No. 1-2, 254-267, doi:10.1108/01443570110358576

[22] Chen, Y. X. (2016). Integrated optimization model for production planning and scheduling with logistics constraints, International Journal of Simulation Modelling, Vol. 15, No. 4, 711-720, doi:10.2507/IJSIMM15(4)CO16

[23] Xiao, N.; Ni, C. D.; Guo, S. J. (2017). Modelling and simulation for production logistics system in industrial enterprises based on hybrid network, International Journal of Simulation Modelling, Vol. 16, No. 1, 157-166, doi:10.2507/IJSIMM16(1)CO3

[24] Meyer, A. (2017). Milk Run Design: Definitions, Concepts and Solution Approaches, Dissertation, KIT Scientific Publishing, Karlsruhe, doi:10.5445/KSP/1000057833

[25] Dematic Corp. Compact Tugger, from http://egeminusa.com/, accessed on 17-02-2018

[26] Egbelu, P. J. (1987). The use of non-simulation approaches in estimating vehicle requirements in an automated guided vehicle based transport system, Material Flow, Vol. 1987, No. 4, 17-32

[27] Le-Anh, T. (2005). Intelligent Control of Vehicle-Based Internal Transport Systems, Dissertation, Erasmus University Rotterdam, Rotterdam 